\title{
Incidence of hospital mortality in polytrauma patients in a tertiary center in Bosnia and Herzegovina
}

\author{
Hadžan Konjo ${ }^{1 *}$, Emira Švraka², Đemil Omerović1, Dijana Avdić
}

${ }^{1}$ Department of Orthopedics and Traumatology, University Clinical Center Sarajevo, Bosnia and Herzegovina, ${ }^{2}$ Faculty of Health Studies Sarajevo, University of Sarajevo, Bosnia and Herzegovina

\section{ABSTRACT}

Introduction: In the late 70 s of the last century, the mortality rate due to polytrauma amounted to $40 \%$. This led to a new approach to this patient category with the goal of improving the treatment outcome. According to the German trauma register, the rate of mortality in polytrauma at the end of the last century was $18.6 \%$. The goal of this study is to determine the incidence of hospital mortality in polytrauma patients in a tertiary institution in Bosnia and Herzegovina.

Methods: We analyzed patient medical records from the Intensive Care Unit of the Clinic of Orthopedics and Traumatology at University Clinical Center Sarajevo, from January 1, 2012 to December 31, 2012.

Results: There were 70 polytrauma patients in 2012, with average age 47.55 (range 8-77) years. Half of the patients were younger than 50 years. Age groups most frequently affected were 61 and older $(25.7 \%)$, $51-60$ years $(24.3 \%)$, and $31-40$ years $(21.4 \%)$. Lethal outcome occurred in 10 patients $(14.3 \%)$, while 60 patients $(85.7 \%)$ survived and were treated until discharge or transfer to a different department. The average Injury Severity Score (ISS) in patients with lethal outcome was 71.50, while in survivors was 37. The largest percentage of lethal outcomes was recorded in cases of traffic accidents.

Conclusion: The mortality rate among hospitalized polytrauma patients in the tertiary institution in Bosnia and Herzegovina is similar to reported mortality rates in other countries with developed healthcare system.

Keywords: incidence; hospital mortality; polytrauma

\section{INTRODUCTION}

The global aim of treatment in case of life-threatened, polytrauma patients is to lower the mortality rate by timely prevention and treatment of shock,

\footnotetext{
*Corresponding Author: Hadžan Konjo, Clinic of Orthopedics \& Traumatology, University Clinical Center Sarajevo, Bolnička 25, 71000 Sarajevo, Bosnia and Herzegovina,

E-mail: hadjank@hotmail.com
}

Submitted: 15 February 2016 / Accepted: 30 March 2016

DOI: http://dx.doi.org/10.17532/jhsci.2016.331

UNIVERSITY OF SARAJEVO FACULTY OF HEALTH STUDIES shortening the duration of tissue hypoperfusion and hypoxia - prehospital and harmonization of prehospital and hospital level toward definitive care, i.e. team work through established trauma system (1).

The incidence of mortality in polytrauma patients depends on a number of factors related to all levels of healthcare. During the late 1970s and early 1980 s the percentage of lethal outcomes in polytrauma patients significantly decreased with the development of advanced trauma centers in the USA and Germany, which included special programs of 
education and the introduction of specific protocol in regards to the approach to these patients. One of the countries that has a completely elaborated the trauma system is Australia. These models are transferred to a large number of countries around the world, and produce similar results. The largest percentage of lethal outcomes in polytrauma patients occurs during the first 24 hours, in other words, directly after the accident. In polytrauma, a specific percentage of deaths are unavoidable and some injuries because of their localizations cause death shortly after, and no treatment can delay that outcome (2).

In the late 70 s of the last century, the mortality rate of polytrauma was around $40 \%$, which led to development of new approach to this category of patients with the goal of improving the treatment outcome.

Hass et al. reported on the basis of retrospective analysis at Humboldt University Clinic in Berlin, that the rate of mortality decreased from $40 \%$ in 1972 to $18 \%$ in 1991 (3). Similar results were published by Regel et al. from Unfallchirurgische Klinik Hannover, Germany, in the study of 3406 patients (4). Probst et al. conducted long retrospective study of period 1975-2004 with 4849 patients. Lethal outcome in the first, second and third decade had a decreased to $37 \%, 22 \%$, and $18 \%$, respectively (5). According to data published in the German Trauma register DGU (Deutsche Gesellchaft fur Unfallchirurgie); the rate of mortality of polytrauma at the end of the last century was $18.6 \%(6,7)$. Ruchholtz et al. conducted a retrospective study in 105 surgical clinics in Germany, from which 11.013 patients were included in a period 1993-2005. The rate of mortality from $22.8 \%$ in 1993 decreased to $18.7 \%$ in 2005 according to this study published by the Trauma register DGU (8).

The Injury Severity Score (ISS) is an established medical score for assessing the trauma severity. It correlates with mortality, morbidity and hospitalization time after trauma. In a study of Mathess et al. in patients with ISS 36.8+/-10.9 $(\geq 25)$ mortality rate was 31.7\% (9). According to American College of Surgeons in a group with ISS between 16-24, the mortality rate was about $6 \%$, while in the group with ISS > 24 it was about $32 \%$ (10-13).

Bosnia and Herzegovina healthcare system is complex and not well developed. There are no published data about the mortality in hospitalized polytrauma patients. Our aim is to analyze the incidence of mortality and characteristics of the hospitalized polytrauma patients in a tertiary healthcare institution in Bosnia and Herzegovina.

\section{METHODS}

We used patient's medical records dating January $1^{\text {st }}$ to December $31^{\text {st }} 2012$, at the Intensive Care Unit (ICU) of the Clinic of Orthopedics and Traumatology. The study included all polytrauma patients treated in that period at the ICU. Polytrauma was defined as significant injuries of three or more points in two or more different anatomic Abbreviated Injury Scale (AIS) regions in conjunction with one or more additional variables from the five physiologic parameters (14-15). We recorded multiple medical and demographic parameters from the medical records of the patients, including their ISS score.

Most commonly used scales for assessing the severity of trauma are the Trauma score (TS), Abbreviated Injury Scale (AIS), Injury Severity Scale (ISS), Revised Trauma Score (RTS), Glasgow Coma Scale (GSC), TRISS system and others $(3,16)$.

\section{RESULTS}

There were 70 patients treated during year 2012 at the Intensive Care Unit of the Clinic for Orthopedic Surgery and Traumatology, Clinical Center of the University of Sarajevo, Bosnia and Herzegovina. The highest percentage of polytrauma patients were observed at age group of 61 years and older $(25.7 \%)$, and from 51-60 years (24.3\%). The average age of patients with polytrauma was 47.55 (range 8-77) years. Male patients were dominant with $77.11 \%$ $(n=54)$, compared to females with $22.9 \% \quad(n=16)$. The difference in polytrauma frequency in the age groups related to gender were not significant $(\chi 2=5.592 ; p>0.05)($ Table 1$)$.

Among male patients the most prevalent occupation was worker $(51.9 \%)$, while the women were most often housewives $(56.3 \%)$ (Table 2).

The most common cause of injury in both genders was fall in $40(57.1 \%)$ cases, followed by traffic accident in $22(31.4 \%)$ cases, while injury by firearms 
was recorded in only one male patient $(1.9 \%)$. The causes of polytrauma related to gender are shown in Table 3.

Lethal outcome occurred in 10/70 (14.3\%) cases treated at Intensive Care Unit, while 60/70 (85.7\%) survived, were treated, and then transferred to different department. The mortality rate according to causes of polytrauma is shown in Table 4. The incidence of mortality was significantly different according to the cause of injury. A patient with firearm injuries had the lethal outcome, while the highest incidence of mortality had been recorded among patients injured in traffic accidents $(27.3 \%)$ and falls $(7.5 \%), \chi 2=11.701 ; \mathrm{p}=0.008$.

The average ISS score in patients with lethal outcome due to polytrauma was 71.50 , while in the patients who survived it was 37 (Table 5).

\section{DISCUSSION}

Polytrauma occurs in 3-8\% of all traumas, but it is the leading cause of mortality and has significant impact on morbidity. Mortality at the site of injury is $50-80 \%$. Trauma outcome studies are

TABLE 1. Incidence of polytrauma in different age groups in Bosnia and Herzegovina

\begin{tabular}{lccc}
\hline \multirow{2}{*}{$\begin{array}{l}\text { gge } \\
\text { group }\end{array}$} & \multicolumn{2}{c}{ Gender, $\mathrm{n}(\%)$} & \multirow{2}{*}{\begin{tabular}{c} 
Total \\
\cline { 2 - 3 } $\mathrm{n}(\%)$
\end{tabular}} \\
\hline $8-20$ & $2(3.7)$ & $1(6.3)$ & $3(4.3)$ \\
$21-30$ & $7(12.9)$ & $3(18.8)$ & $10(14.3)$ \\
$31-40$ & $10(18.5)$ & $5(31.3)$ & $15(21.4)$ \\
$41-50$ & $4(7.4)$ & $3(18.8)$ & $7(10.0)$ \\
$51-60$ & $15(27.8)$ & $2(12.5)$ & $17(24.3)$ \\
$61-77$ & $16(29.6)$ & $2(12.5)$ & $18(25.7)$ \\
Total & $54(77.1)$ & $16(22.9)$ & $70(100)$ \\
\hline
\end{tabular}

TABLE 2. Profession according to gender in baseline sample

\begin{tabular}{lccc}
\hline Profession & \multicolumn{3}{c}{$\mathrm{n}(\%)$} \\
\cline { 2 - 4 } & Male & Female & Total \\
\hline Housewife & $0(0.0)$ & $9(56.3)$ & $9(12.9)$ \\
Retired & $16(29.6)$ & $1(6.3)$ & $17(24.3)$ \\
Worker & $28(51.9)$ & $3(18.8)$ & $31(44.3)$ \\
Clerk & $5(9.3)$ & $3(18.8)$ & $8(11.4)$ \\
Student & $5(9.3)$ & $0(0.0)$ & $5(7.1)$ \\
Total & $54(77.1)$ & $16(22.9)$ & $70(100)$ \\
\hline
\end{tabular}

$\chi^{2}=18.661 ; p<0.05$ very important as they serve as a medical audit and a measure for quality of care provided to trauma patients in the prehospital and in hospital setting. These studies are also useful tool to revise, renew and improve assessment and therapeutic methods in early trauma care (17). In our study the most common mechanism of injury in both gender was fall in $28(51.9 \%)$ male and $12(75 \%)$ female patients, followed by traffic accident - 19 (35.2\%) male and $3(18.8 \%)$ female patients. In the study by El Mestoui Z. et al., Incidence and etiology of mortality in polytrauma patients in a Dutch level I trauma center, the predominant mechanisms of injury were falls from height $(n=55,26.8 \%)$, followed by bicycle accidents $(\mathrm{n}=33,16.1 \%)$. This may be because bicycles are a very common mode of transportation in Amsterdam. Remarkably, most of these patients sustained CNS injury (87.9\%) (17).

The most common cause of polytrauma in Croatia are traffic accidents (67\%) and falls from height $(31 \%)$ while the average age of polytraumatised patient is 40 years (18).

In the Intensive Care Unit of the Clinic of Orthopedics and Traumatology in 2012 due to multiple traumas there were $10(14.3 \%)$ deaths. Patients

TABLE 3. Causes of polytrauma in patients in Bosnia and Herzegovina

\begin{tabular}{lccc}
\hline Injury type & \multicolumn{3}{c}{$\mathrm{n}(\%)$} \\
\cline { 2 - 4 } & Male & Female & Total \\
\hline Fall & $28(51.9)$ & $12(75.0)$ & $40(57.1)$ \\
Traffic accident & $19(35.2)$ & $3(18.8)$ & $22(31.4)$ \\
Blunt trauma & $6(11.1)$ & $1(6.3)$ & $7(10.0)$ \\
Firearms & $1(1.9)$ & $0(0.0)$ & $1(1.4)$ \\
Total & $54(77.1)$ & $16(22.9)$ & $70(100)$ \\
\hline
\end{tabular}

$\chi^{2}=2.806 ; p>0.05$

TABLE 4. Mortality rate according to the cause of injury

\begin{tabular}{lccc}
\hline & \multicolumn{2}{c}{ Mortality, $\mathrm{n}(\%)$} & Total \\
\cline { 2 - 3 } & No & Yes & $\mathrm{n}(\%)$ \\
\hline Cause of injury & & & \\
Fall from height & $37(92.5)$ & $3(7.5)$ & $40(100.0)$ \\
Firearms & $0(0)$ & $1(100)$ & $1(100.0)$ \\
Traffic accident & $16(72.7)$ & $6(27.3)$ & $22(100.0)$ \\
$\quad$ Blunt trauma & $7(100.0)$ & $0(0.0)$ & $7(100.0)$ \\
Total & $60(85.7)$ & $10(14.3)$ & $70(100.0)$ \\
\hline
\end{tabular}

$\chi^{2}=11.701 ; p=0.008$ 
TABLE 5. Average ISS score in polytrauma patients according to outcome

\begin{tabular}{lcccccccc}
\hline $\begin{array}{l}\text { Lethal } \\
\text { outcome }\end{array}$ & $\mathrm{n}$ & $\begin{array}{c}\text { ISS } \\
\text { mean }\end{array}$ & SD & SEM & \multicolumn{2}{c}{$95 \% \mathrm{Cl}$} & Minimum & Maximum \\
\cline { 6 - 7 } & & & & & Lower & Upper & & \\
No & 60 & 37.23 & 12.93 & 1.67 & 33.89 & 40.57 & 17.00 & 63.00 \\
Yes & 10 & 71.50 & 3.53 & 1.11 & 68.97 & 74.02 & 66.00 & 75.00 \\
\hline
\end{tabular}

$F=68.52 ; p<0.05$, ISS - Injury severity score

who have had a lethal outcome had an average ISS score of 71.5. Based on the obtained data, conditions were created for the guidelines that are given based on the ROC curve which indicates that based on the ISS, some patients require special attention in regards to those with multiple trauma whose ISS $>63$ because the incidence of mortality increases linearly after this cut-off ISS score.

In order to improve the quality of care and protect polytrauma patients, results should be constantly compared with the previous, as well as with other institutions, which in their own environment have a register of polytrauma, which must be based on the application of the trauma scoring scale. Without such parameters, it is impossible to compare the results and the quality of care for polytrauma patients in us with any other environment.

This study has proven that the majority of patients with multiple traumas, who died due to their injuries, mostly had a traffic accident. The team for the care of these patients consisted on average of 5 nurses and technicians, and the mortality rate in the first 24 hours was approximately $60 \%$ compared to the total number of patients who had a lethal outcome.

In $\mathrm{B} \& \mathrm{H}$, there is no system developed strategy for care of patients with polytrauma, and there are not even elementary protocols of emergency diagnostic and therapeutic procedures for severe polytrauma patients. The severity of the trauma can be compared only using the scale in traumatology. The scales for evaluation of trauma have been used in the world for more than 20 years. In $\mathrm{B} \& \mathrm{H}$, there is no obligation for the introduction of the scale for the evaluation of trauma in traumatology. One of the most famous experts in this field, $\mathrm{H}$. Champion proved that statistics is a powerful replacement for clinical reporting, with the purpose of developing a trauma care system based on the data.

Health staff involved in the care of injured in $\mathrm{B} \& \mathrm{H}$ have no legal obligation for special education, which would ensure the quality of the overall care of patients with polytrauma, as it is standard in Western countries.

Without the right data on the current situation in our trauma center it is not possible to provide a projection that will improve outpatient services (outpatient emergency medical services, helicopter rescue service, the Office for Protection and Rescue) and hospital care, and lead to progress.

\section{CONCLUSIONS}

The mortality rate among hospitalized polytrauma patients in the tertiary institution in Bosnia and Herzegovina is similar to reported mortality rates in other countries with developed healthcare system.

\section{CONFLICT OF INTEREST}

The authors declare no conflict of interest.

\section{REFERENCES}

1. Bouzat $P$, Ageron FX, Brun J, Levrat A, Berthet M, Rancurel E, et al. A regional trauma system to optimize the pre-hospital triage of trauma patients. Crit Care 2015;19:111.

http://dx.doi.org/10.1186/s13054-015-0835-7.

2. Benson AB, Moss M. Trauma and Acute Respiratory Distress Syndrome: Weighing the Risk and Benefits of Blood Transfusions. Anesthesiology 2009; 110(2): 216-7. http://dx.doi.org/10.1097/aln.0b013e3181948ac0.

3. Haas NP, Hoffmann RF, Mauch C, Fournier C, Sudkamp NP. The management of polytraumatized patients in Germany. Clin Orthop Relat Res 1995; (318): 25-35.

4. Regel G, Lobenhoffer P, Lehmann U, Pape HC, PohlemannT, et all. Results of treatment of polytraumatized patients. A comparative analysis of 3406 cases between 1972 and 1991. Unfallchirurg 1993; 96(7): 350-62.

5. Probst C, Pape HC, Hildebrand F, Regel G, Mahike L, et all. 30 years of polytrauma care: An analysis of the change in strategies and results of 4849 cases treated in single institution. Injury 2009; 40(1): 77-83. http://dx.doi.org/10.1016/j.injury.2008.10.004.

6. Rixen D, Raum M, Buillon B, Schlosser LE, Neugebauer E. Predicting the outcome in severe injuries: ana analysis of 2069 patients from the trauma register of the German Society of Traumatology (DGU). Unfallchirurg 2001;104(3): 230-9.

http://dx.doi.org/10.1007/s001130050719. 
7. Bardenheuer M, Obertacke U, Waydhas C, Nast-Kolb D. Epidemiology of the severely injured patient. A prospective assessment of preclinical and clinical management. Unfallchirurg 2000; 103(5): 355-63. http://dx.doi.org/10.1007/s001130050550.

8. Ruchholtz S, Lefering R, Paffrath T, Oestern HJ, Neugebauer E, et al. Rückgang der Traumaletalität. Dtsch Arztebl 2008; 105(13): 225-31.

9. Mathess G, Seifert J, Bogatski S, Steinhage K, Ekkernkamp A, et al. Age and survival likelihood of polytrauma patients. Local tailoring" of the DGU prognosis model. Unfallchirurg 2005; 108(4): 288-92.

10. American College of Surgeons. National Trauma Data Bank Report 2004. ACS 2004. 25.

11. American College of Surgeons. National Trauma Data Bank Report 2005. ACS 2005.

12. American College of Surgeons. National Trauma Data Bank Report 2006. ACS 2006.

13. American College of Surgeons. National Trauma Data Bank Annual Report 2007. ACS 2007.
14. Pape HC, Lefering R, Butcher N, Peitzman A, Leenen L, Marzi I, et al. The definition of polytrauma revisited: An international consensus process and proposal of the new 'Berlin definition'. J Trauma Acute Care Surg. 2014;77(5):780-786.

http://dx.doi.org/10.1097/TA.0000000000000453.

15. Butcher NE, Balogh ZJ. Update on the definition of polytrauma. Eur $\mathrm{J}$ Trauma Emerg Surg. 2014;40(2):107-11.

http://dx.doi.org/10.1007/s00068-014-0391-x

16. Thomas S, Sundararajan R, Walsh M, et al. Mayority of the 50 states effective trauma systems. J Trauma 2006; 61(3): 767-9. http://dx.doi.org/10.1097/01.ta.0000231765.94107.b1.

17. El Mestoui Z, Jalalzadeh H, Giannakopoulos GF, Zuidema WP. Incidence and etiology of mortality in polytrauma patients in a Dutch level I trauma center. European journal of emergency medicine: official journal of the European Society for Emergency Medicine. 2015.

18. Gržalja N, Marinović M, Štiglić D, Saftić I, Primc D, Oštrić M, Grgurev M, Martinović G, Lalić S \& Cicvarić, T. Treatment of polytrauma. Medicina Fluminensis, 2013; 49(4): 447-453. 